\title{
0 exílio de Darcy Ribeiro e Ángel Rama: intelectuais, cultura e política na América Latina
}

\author{
Helena Bomeny* \\ Alejandra Josiowicz***
}

\section{Resumo}

0 texto trata do encontro de dois intelectuais, o brasileiro Darcy Ribeiro, antropólogo, ficcionista e intelectual público e Ángel Rama, crítico literário, escritor e ensaísta uruguaio . 0 encontro foi provocado pelo exílio de um deles, seguido do exílio de outro. Os exílios de Darcy Ribeiro (1922-1997) e Ángel Rama (1926-1983) se deram em momentos distintos e em países diferentes. 0 de Darcy Ribeiro começa no Uruguai em 1964. Data dali seu encontro com Ángel Rama. Permanece em Montevidéu até 1968, quando retorna ao Brasil acreditando em notícias sobre a liberalização do regime político decorrente do Golpe de 1964. As autoras tratam do percurso de ambos, das afinidades e, especialmente, do que os distingue como intelectuais comprometidos com a reflexão sobre seus países tendo o exílio como vetor central.

\section{Palavras-chave}

Intelectuais. Exílio. Nação.

\begin{abstract}
This paper approaches the relationship between Darcy Ribeiro - anthropologist, writer and intellectual - and Ángel Rama - literary critic, writer and essayist. They met as a consequence of each one's exile, which happened in different moments and countries. Ribeiro's exile began in Uruguai in 1964, where he met Ángel Rama. Ribeiro stayed in Montevidéu until 1968, when he returned to Brazil after hearing news about the softening of the political regime implemented in 1964 following the military coup. The paper discusses these authors' trajectories and the affinities between them, and particularly their status as intellectuals committed to reflecting about their countries' dilemmas in relation to the experience of exile.
\end{abstract}

\section{Keywords}

Intellectuals. Exile. Nation.

\footnotetext{
* Helena Bomeny é Doutora em Sociologia pelo Instituto Universitário de Pesquisas do Rio de Janeiro (IUPERJ) e Professor Titular de Sociologia da Universidade do Estado do Rio de Janeiro (UERJ). É autora, entre outros, do livro Darcy Ribeiro. Sociologia de um indisciplinado. Belo Horizonte, Editora da UFMG, 2001.

** Alejandra Josiowicz é Doutora em Spanish and Portuguese pela Princeton University. Atualmente, realiza Pós-doutorado no Centro de Pesquisa e Documentação de História Contemporânea do Brasil (CPDOC) da Fundação Getúlio Vargas (FGV). E-mail: alejandra.josiowicz@gmail.com.
} 


\section{Introdução}

Este texto trata do encontro de dois intelectuais provocado pelo exílio de um deles, seguido do exílio de outro. Os exílios de Darcy Ribeiro (19221997) e Ángel Rama (1926-1983) se deram em momentos distintos e em países diferentes. O de Darcy Ribeiro começa no Uruguai em 1964. Data dali seu encontro com Ángel Rama. Permanece em Montevidéu até 1968, quando retorna ao Brasil acreditando em notícias sobre a liberalização do regime político decorrente do Golpe de 1964. Três meses após sua chegada, em dezembro de 1968, o governo militar decretou o Ato Institucional N.5, documento que instaura o período mais violento da ditadura. Darcy Ribeiro é preso, até que, em 1969, absolvido dos crimes pelos quais havia sido acusado, foi "convidado" pelos militares para deixar o Brasil. O exílio agora será na Venezuela, onde novamente se encontra com Ángel Rama. Curto período. Em 1970 deixa a Venezuela, seguindo para o Chile e o Peru, retornando ao Brasil definitivamente em 1976. Esse período entre 1964 e 1976 constitui a que poderia ser considerada sua experiência latinoamericana mais forte, com consequências fundamentais para a ampliação do universo reflexivo sobre o Brasil, consolidando nele o que cultivava como pertencimento latino-americano.

Por seu lado, Ángel Rama sai do Uruguai em 1970 para lecionar na Universidade de Porto Rico e já não poderá voltar até sua morte abrupta em 1983. Experimentou nos treze anos que passou entre Porto Rico, Venezuela, Estados Unidos e França o deslocamento, a instabilidade e a falta de pertencimento a uma comunidade cívica. Na sua extensa produção de ensaios, artigos e livros no período sobre a literatura e a cultura na América Latina, Rama questionou o que chamou várias vezes de "nacionalismo provinciano", em favor de uma aspiração latinoamericanista e de um ideário cosmopolita. Em 1973, o golpe militar no Uruguai o encontra lecionando na Universidade de Venezuela, após uma estada de dois anos na Universidade de Porto Rico, após a qual deveu adotar a nacionalidade venezuelana. Em 1978, viaja aos Estados Unidos e trabalha em várias universidades, no Middlebury College, na Universidade de Maryland e na Universidade de Princeton. Tendo solicitado o visto permanente para trabalhar na Universidade de Maryland, seu pedido foi rejeitado pelas autoridades do país, pelo que decidiu trasladar-se à França, graças ao oferecimento de uma bolsa Guggenheim. Entre 1973 e 1983, ano de seu falecimento em um acidente aéreo, a trajetória e o pensamento 
de Rama revelam a centralidade cada vez maior da questão do exílio como estruturante de sua concepção do intelectual, ligada à progressiva dissolução da rede de sociabilidade e interlocução latino-americana da qual ele fez parte, mas também à importância de sua experiência transnacional e, especificamente, seu contato com intelectuais latino-americanos exilados, como é o caso de Darcy Ribeiro.

Ainda que em momentos e espaços distintos, Rama e Ribeiro coincidem não só em vários pontos de suas trajetórias, mas também no cultivo de uma ideologia latino-americanista que, no caso de Ribeiro, se intensifica a partir de 1964, com sua experiência fora do Brasil. Em Rama, o comprometimento com o horizonte latino-americano havia começado antes, dada sua participação, desde 1959, na revista Marcha, de ideologia latinoamericanista, além dos laços que estabeleceu com Antônio Candido desde inícios de 1960. ${ }^{1}$ Mas o que talvez seja ainda mais central para este trabalho: em ambos, a incidência da questão do exílio e sua relação com a experiência da derrota. Edward Said já relacionou a figura do intelectual com a condição do exilado: é aquele que toma distância de construções de identidade demasiado fixas ou essencialistas e que tem a habilidade de mediar entre dinâmicas étnicas, religiosas e políticas diferentes e, inclusive, opostas, ao interior da vida social, sem por isso tornar-se alheio a ela. ${ }^{2} \mathrm{O}$ exílio é central para Darcy Ribeiro e Ángel Rama, como condição biográfica mas também metafórica, dado seu ajustamento sempre incompleto, na fronteira, como migrantes ou viajantes entre as culturas e as sociedades. Nesse sentido, analisamos não só a produção escrita, mas também a trajetória biográfica desses intelectuais, entendendo vida e trajetória como interagindo em forma dinâmica, conjugando o público com o privado, o intelectual com o pessoal, o comunitário com o biográfico, e apontando para o contexto político mais amplo. Os governos ditatoriais que se instauraram em vários países da América Latina no período e a modernização autoritária que eles acarretaram causaram a debilitação dos departamentos universitários e dos

\footnotetext{
${ }^{1}$ Ver, sobre o tema: ROCCA, Pablo. Ángel Rama, Emir Rodríguez Monegal y el Brasil: Dos caras de un proyecto latinoamericano. Montevideo, Banda Oriental, 2006. Capítulo 6, "Antonio Candido y Ángel Rama". Ver também: Un proyecto latino-americano. Antonio Candido \& Angel Rama. Correspondencia. Ed. Pról.; e notas de Pablo Rocca. Montevideo, Ed. Estuario, 2016.

2 SAID, Edward. Representations of the Intellectual. New York, Vintage books, 1994. Dentre a longa tradição teórica sobre o pensamento intelectual sobre o exílio (não faremos uma listagem extensiva por questões de espaço) é importante ressaltar o texto recente: BURKE, Peter, Exiles and Expatriates in the History of Knowledge, 1500-2000. Waltham, Brandeis Univ. Press, 2017.
} 
espaços de inserção institucional, o que teve como consequência o exílio de muitos intelectuais nas décadas de 1960 e 1970, em vários países da América Latina e nos Estados Unidos. Tanto Darcy Ribeiro quanto Ángel Rama foram mobilizados pelo modo como os intelectuais desse momento posicionaram-se diante do fracasso dos projetos das esquerdas na América Latina e da emergência de regimes ditatoriais. $\mathrm{O}$ momento da derrota implica a necessidade de enfrentar, de tramitar a melancolia, o luto, a ruína das utopias. ${ }^{3}$ Segundo Rama, a "literatura da derrota" pode se revelar ainda mais produtiva para pensar a relação entre literatura e política do que a cultura das utopias e das celebrações. ${ }^{4}$ No caso de Darcy Ribeiro - e isso é o que mais nele atrai Rama - a derrota tramita-se a partir de um impulso polêmico, quase messiânico, que não perde sua carga utópica, o que, ao fim e ao cabo, acaba repolitizando a reflexão sobre a cultura. ${ }^{5}$

Tomamos a biografia intelectual como gênero e modelo teóricometodológico que aponta para as contradições e particularidades na autonomização e profissionalização dos intelectuais na época. ${ }^{6} \mathrm{E}$ que também ajuda a recuperar a centralidade das redes e da sociabilidade entre os intelectuais, tanto no interior do âmbito latino-americano quanto com relação aos Estados Unidos. Partimos de gêneros de tipo autobiográfico (diários, cartas e memórias), além de ensaios, nos quais os intelectuais refletem sobre si mesmos, criam e recriam imagens de si mesmos e redes de sociabilidade. ${ }^{7} \mathrm{Na}$ chave da sociologia dos intelectuais, seguimos a

\footnotetext{
${ }^{3}$ Sobre o tema da "derrota" nas produções culturais e literárias da pós-ditadura, ver: Idelber Avelar. The Untimely Present: Post-dictatorial Latin American Fiction and The Task of Mourning. Durham, Duke Univ. Press, 1999.

${ }^{4}$ RAMA, Ángel. "La riesgosa navegación del escritor exiliado". Nueva Sociedad. Nro. 35. Março-abril 1978, p. 99-100.

${ }^{5}$ Exemplar do que se mantém em Darcy Ribeiro a despeito das derrotas é sua própria declaração apaixonada: "Fracassei em tudo o que tentei na vida. Tentei alfabetizar as crianças brasileiras, não consegui. Tentei salvar os índios, não consegui. Tentei fazer uma universidade séria e fracassei. Tentei fazer o Brasil desenvolver-se autonomamente e fracassei. Mas os fracassos são minhas vitórias. Eu detestaria estar no lugar de quem me venceu". Disponível em: www.contextolivre.com. br/2013/11/darcy-fracassei-em-tudo-o-que-tentei-na.html. Acesso em agosto de 2017.

${ }^{6}$ DOSSE, François. O desafio biográfico. Escrever uma vida. São Paulo, Edusp, 2009.

${ }^{7}$ Dada a maior atenção que a crítica tem dado aos ensaios mais extensos de Ángel Rama, como Rubén Darío y el modernismo (1970), Transculturación narrativa en América Latina (1982), La ciudad letrada (1984) e Las máscaras democráticas del modernismo (1985), preferimos analisar materiais que conjugam a reflexão sobre o intelectual - sobretudo no caso de ensaios menos conhecidos da última etapa de sua produção - com textos de carácter autobiográfico, como é o caso do diário e as cartas.
} 
linha da exploração histórico-cultural, que tem apontado para os discursos e posições anti-intelectualistas de uma fração dos intelectuais latinoamericanos das décadas de 1960 e 1970: definimos o anti-intelectualismo como categoria teórica, característica do contexto das décadas de 1960 e 1970, que caracteriza a posição ideológica adotada por certos intelectuais radicais, que priorizavam o valor da política e sua lógica de eficácia e instrumentalidade por sobre a especificidade da própria atividade intelectual e a produção científico-cultural. ${ }^{8}$

Isso nos leva a uma das diferenças fundamentais entre Ribeiro e Rama: enquanto eles compartilhavam receios similares diante da especialização e da profissionalização que veem simbolizadas na academia norte-americana, divergem no modo pelo qual cada um concebe o papel do intelectual. Ángel Rama pensou o intelectual a partir da ambivalência entre dois modelos: por um lado, com Karl Mannheim, considerou os intelectuais como capazes de perspectiva crítica, independente e sintética a respeito dos dilemas da sociedade como um todo. ${ }^{9}$ Por outro lado, seus textos também deixam transparecer uma posição mais próxima de Antonio Gramsci, sobretudo na sua teorização do papel orgânico de novas camadas de intelectuais a respeito das classes populares. ${ }^{10} \mathrm{Em}$ sua perspectiva, o intelectual seria ao mesmo tempo um dissidente, dono de uma visão sintética e inovadora de sua sociedade, e um sujeito inserido ativamente na vida prática, ligado em forma orgânica a certos grupos sociais, cujas circunstâncias compartilha. No caso do Ribeiro há uma recuperação do intelectual político, engajado, preocupado com as necessidades sociais e resistente à profissionalização. No entanto, para ambos a universidade latino-americana constitui lugar de tensão entre modelos opostos: um guiado pelo modelo profissionalizado inspirado na academia norte-americana, especializado e desprovido de

\footnotetext{
${ }^{8}$ Sobre a ideologia anti-intelectual, ver o capítulo 5 "Cuba, patria del antiintelectual latinoamericano". In: GILMAN, Claudia. (2003). Entre la pluma y el fusil. Debates y dilemas del escritor revolucionario en América Latina. Buenos Aires, Siglo XXI. Segundo Florencia Garramuño, esse olhar anti-intelectual caracterizaria A cidade Letrada. Ver GARRAMUÑO, Florencia (2006). El árbol y el bosque: La ciudad letrada y su concepto de poder. Prismas, n.10. pp. 195-197.

${ }^{9}$ Ángel Rama leu e anotou abundantemente os Ensaios de Sociologia da Cultura de Mannheim, com especial atenção à segunda parte, $\mathrm{O}$ problema da Intelligentsia, texto que o influenciou poderosamente. RUFINELLI, Jorge. (1993). Angel Rama, Marcha y la crítica literária latinoamericana en los 60s. Casa de las Américas, vol. 34, n.192.

${ }^{10}$ GRAMSCI, Antonio. (2001). Cadernos do cárcere. vol. 2. Os intelectuais. O princípio educativo. Jornalismo. Rio de Janeiro, Civilização Brasileira.
} 
responsabilidade social; outro politizado, inserido na sociedade, para o qual conhecimento e política são inseparáveis.

\section{0 exílio de um intelectual político}

A trajetória política de Darcy Ribeiro sofreu uma inflexão com o golpe de 31 de março de 1964. Na chefia da Casa Civil do governo João Goulart desde junho de 1963, Darcy se mantinha na capital federal acompanhando de dentro do Planalto os desdobramentos de uma crise política que se agravava na exata proporção em que o governo avançava. Os bastidores do golpe, a atmosfera dos conchavos, o crescimento conspiratório, civil e militar, o desmonte do apoio ao governo por parte dos próprios militares que compunham as forças do Estado, as lideranças de direita personificadas em próceres da República, a intransigência das forças sindicalistas que imprimiam uma feição radicalizada aos movimentos sociais, tudo isso compôs a narrativa memorialística de Darcy em Golpe e Exílio, publicação que integra a coleção “Darcy no Bolso” (Editora UnB, 2010). Brasília, a nova capital, era sua conhecida principalmente pelo obstinado envolvimento com a criação da Universidade. E também o Palácio do Planalto era espaço por ele transitado por já ter ocupado o Ministério da Educação desde agosto de 1962, quando deixava a reitoria da Universidade de Brasília, substituído por Anísio Teixeira (1900-1971), até sua nomeação para a Casa Civil em 1963.

Darcy foi um dos poucos membros do governo que ensaiou organizar uma resistência em defesa do regime democrático. João Goulart declarou que não resistiria, reconhecendo que não havia condições para tanto. "Brizola fez o que podia", completa Darcy, "para forçar Jango à luta armada com o auxílio das tropas sediadas no Rio Grande do Sul e do povo gaúcho. Ele não quis. Exilou-se. No dia 4 de abril, internou-se no Uruguai" (RIBEIRO, 2010, p. 68) O relato de Darcy dá conta de que se manteve no Palácio até que não mais pudesse "(...) Fiquei no meu posto de chefe da Casa Civil, passando pito e dando ordens incumpríveis...)", até ser lembrado pelos novos agentes de que não tinha mais prerrogativas de governo, que já estavam sob novas ordens. As lembranças se esticam:

\footnotetext{
"Os oficiais me olhavam assombrados sem coragem de insistir em que eu saísse. As pessoas que eu chamara, Zé de Catão, meu amigo de infância, e frei Mateus, vice-reitor da UnB, me olhavam com espanto. Iracema sorria, tentando me alegrar. Aquela era
} 
minha hora de chumbo. Hora que eu preferia estar morto a sofrêla: a hora do derrotado. Não disse palavra. Lá fiquei mudo, me roendo. Nem pensar ordenadamente pensava. Só sentia uma dor surda que retesava meus músculos, estirava meus nervos e me deixava pronto para disparar. Para onde? Para nada!". (RIBEIRO, 2010, p.71).

Foi de fato uma resistência inútil. O Ato Institucional n.1, de 9 de abril de 1964, destituiu os direitos políticos de Darcy Ribeiro, além de demitilo de seus cargos de professor da Universidade do Brasil e de etnólogo do Serviço de Proteção ao Índio (SPI). Começava assim uma nova fase de vida, não mais no Brasil, mas no exílio, levando com ele a indignação, a inquietude, o engajamento intelectual e a paixão política de que nunca se distanciou. O trajeto até Montevidéu é descrito com os tons da aventura, dos riscos nem sempre calculados, e de parcerias inestimáveis, como a do amigo Rubens Paiva - morto mais tarde pela violência brutal da tortura pela ditadura - que o resgatou do velho apartamento de reitor da UnB onde procurou se abrigar, a despeito da poeira acumulada. Em trajeto cumprido com percalços do improviso, nosso personagem chega a um hotel em Montevidéu, quando, dois dias depois, foi procurado por Mario Cassinone, reitor da Universidade da República, única do Uruguai, nos seus 150 anos de vida. Combinou uma entrevista e o contratou como professor de Antropologia em regime de dedicação exclusiva. "Era o exílio, a nova vida que se abria à minha frente."

Difícil glamurizar a experiência do exílio por mais intensos que tenham sido os contatos estabelecidos e as experiências ali vividas, por mais ganhos intelectuais que um olhar à distância possa provocar na imaginação dos atores quando de lá olham de forma particularmente distinta suas próprias terras de origem. "O exílio é uma experiência terrível, sobretudo para brasileiros. Temos um país tão grande e variado, tão cheio de sumos, seivas e cores que ser tirado daqui é um desterro. Para todos os exilados, exílio é sofrimento" - na avaliação certeira de Darcy Ribeiro. Como estada não programada, o exilado leva consigo o que já tem à mão. O que não depende de planejamento prévio, talvez até por contingências imprevistas, o que foi vivido mais proximamente à retirada de seu país. Além disso, como nos ensinou Ángel Rama, "no es una conjugación fácil. La palabra exilio tiene un matiz precario y temporero: parece aludir a una situación anormal, transitoria, algo así como un paréntesis que habrá de cerrarse con el puntual retorno a los orígenes." O que não foi planejado, o que é precário 
e temporário obriga os atores a apressadamente arranjar seus pertences, materiais e intelectuais, com o que for possível na pressa. Este nos pareceu ser um ponto forte na recuperação do sentido que se pode atribuir ao exílio de Darcy Ribeiro. Em sua bagagem, de forma absoluta, o que mais recentemente o mobilizara de corpo e alma: a invenção de uma universidade, concebida como "uma universidade moderna capaz de, além de cumprir as tarefas correntes de ensino e pesquisa, completar a cidade-capital com o núcleo científico e cultural, que não lhe pode faltar, e, ainda, proporcionar aos poderes públicos a indispensável assessoria no campo do planejamento e da assistência técnica e científica", conforme anunciou o presidente João Goulart na mensagem presidencial. Uma universidade filha da utopia e de um sonho de reparação (BOMENY, 2016). Sonho, movido pela aura e magia de fundação de um país com a ousadia cultural de uma universidade; reparação de um experimento abortado por força do autoritarismo do Estado Novo fechando por decreto, em 1939, a Universidade do Distrito Federal (UDF), então Rio de Janeiro, onde circulavam, além de professores estrangeiros convidados, nossos educadores pioneiros, Anísio Teixeira e Darcy Ribeiro, entre outros. Duas universidades, duas capitais ofendidas pela força da repressão.

Darcy associou ao magistério de Antropologia a oportunidade de pensar o que qualificou civilização americana. Pensar o Brasil no contexto latino-americano; defender a América Latina como parte de uma utopia de integração cultural e política muito própria de parcela importante de intelectuais latino-americanos. Eram tempos de reforma também no Uruguai. Reforma universitária, como a que vinha ocupando a pauta intelectual brasileira sem ainda uma expressão nacional mais consolidada, como acabou acontecendo em 1968, e para a qual a experiência de Brasília, em muitas dimensões, foi modelo. Descentralizar, extinguir o sistema de cátedra, flexibilizar estruturas de modo a autorizar invenções e estimular a imaginação científica. Uma aposta da razão liberta como solução para quebrar estruturas obsoletas. Darcy Ribeiro encontrou no reitor que o capturou no hotel em Montevidéu motivação para promover a discussão no Uruguai. O primeiro trabalho tratou disso, de animar o seminário sobre reformas da universidade. A UnB se impunha soberana! Darcy conduziu as discussões levando o projeto da UnB, comparando-o com o que encontrava na Universidade do Uruguai, mas não só. Atuou com igual empenho na Venezuela, no Chile e no Peru. As conferências que proferia a propósito das reformas foram publicadas em livro La universidad latinoamericana, editado 
na Venezuela, no Chile e no México, tendo recebido na edição brasileira o título A universidade necessária. Ter transitado pelos países irmãos influenciou, de forma nítida, a produção do próprio Darcy. Angel Rama registra a presença dos brasileiros exilados reconhecendo a influência que eles próprios receberam dos países por onde passaram:

"Dentro de este grupo hay uno que hizo una experiencia inédita, cuyos resultados futuros pueden ser de los más ricos. Se trata del grupo intelectual brasileño, que a la caída del régimen de João Goulart, a manos de los militares (1964), se distribuyó entre los países hispanoamericanos, el cual está ahora en un proceso de reincorporación progresiva a la vida del Brasil. Fue una experiencia inédita, pues el Brasil vivió de espaldas a la América española y ésta a su vez vivió entre la ignorancia o el temor de ese país desconocido que parecía tan grande y amenazador en las cartas geográficas. A pesar de pertenecer al común denominador de América Latina han sido muy escasas las comunicaciones culturales o políticas entre Brasil e sus vecinos. Estos intelectuales descubrieron la existencia de Hispanoamérica, no sólo en sus singularidades políticas sino también en sus modos culturales: Mario Predroza en Chile, Ferreira Gullar en Buenos Aires, Darcy Ribeiro en Montevideo, Francisco Julião en México, si por un lado se constituyeron en embajadores de una cultura ignota ante los grupos políticamente afines, por la otra hicieron experiencias de culturas desconocidas...". ${ }^{11}$

Universidade e transformação do mundo. O livro do exílio publicado posteriormente no Brasil - A universidade necessária - é exemplar do cruzamento que marcou a década intelectual dos 60 entre política e cultura. E, em uma dimensão importante para esta reflexão, a interlocução fortalecida entre intelectuais latino-americanos na convivência no exílio. $\mathrm{O}$ livro é talvez a expressão mais visível da saída de uma reflexão nacional para um aporte de América Latina. Darcy leva para o exílio a memória de todo o processo de discussão que fez da Universidade de Brasília o exemplo, posteriormente considerado na Reforma Universitária de 1968 no Brasil, a despeito de todos os processos de ruptura a que esteve sujeita já no início do regime militar. A UnB simbolizava a possibilidade de combinar

11 "La riesgosa navegación del escritor exiliado". Nueva Sociedad. Nro. 35. Março-abril 1978, p. 99-100. 
ciência, imaginação e mobilização política. Universidade comprometida com a utopia de um país novo, responsável por redesenhar uma estrutura considerada obsoleta, autoritária, excludente e assentada em procedimentos rígidos e centralizadores. $\mathrm{O}$ vínculo entre modernização e transformação social com experiência universitária constituiu-se bandeira na instauração da universidade. Missão explícita, exposta aos que aceitavam o desafio de construí-la no espaço ainda vazio da nova capital. Um sonho que dependeria da vontade política dos atores envolvidos no processo de construção da universidade cultivada em suas especialidades como cientistas, artistas plásticos, arquitetos, cineastas e intelectuais.

A fala de Darcy no Prólogo à edição brasileira não deixa dúvida a respeito do papel mobilizador que a juventude desempenharia no ambiente universitário. Esse segmento da população traduzia o que potencialmente se esperava nessa combinação de cultura e política: rebeldia orientada para transformação, alimentada pela consciência dos efeitos perversos da estrutura classista, repressiva e embrutecedora sobre a experiência social. Nas nações subdesenvolvidas - em nosso cenário latino-americano -, a rebeldia é "uma forma de expressão da sua inconformidade com o atraso de suas sociedades". (RIBEIRO, 2010, p. 2) Nas desenvolvidas, tal rebeldia "aponta contra as sombrias perspectivas que se lhes abrem de amarga acomodação às chamadas 'sociedades de consumo'". Completa Darcy:

\footnotetext{
“Trata-se, nos dois casos, de posturas essencialmente políticas e radicais que não se propõem apenas superar alguns arcaísmos da universidade e do regime, mas se lançam contra a estrutura de poder a que ambos servem, com a deliberação de transformá-la revolucionariamente".
}

(RIBEIRO, 2010, p. 3).

Os jovens compõem a vanguarda desse movimento, primeiro por sua condição privilegiada perante a juventude de trabalhadores. Formam eles uma camada socialmente privilegiada. Segundo, e não menos importante, a atitude de rebeldia revolucionária é "ativada por sua educação, também privilegiada, que lhe faculta uma consciência lúcida sobre o caráter retrógrado da ordem vigente". O combate tem um sentido de urgência. São jovens da mesma geração que serão jovens por pouco tempo, e apenas por um tempo determinado poderão se envolver na cruzada proposta à sua atuação. Eles próprios serão capturados pela moenda da vida, disciplinando-se pelo trabalho, contraindo compromissos familiares fora 
de seu ambiente original sob proteção dos pais, respondendo à dinâmica competitiva da vida profissional.

"Fundada nestas motivações profundas, de natureza estrutural e ideológica e no seu caráter geracional, a rebeldia estudantil tende a aprofundar-se e a generalizar-se cada vez mais, bem como a reiterar-se pela renovação constante de seus contingentes. Por isso mesmo, ela representará um papel relevante na luta pela edificação de novos tipos de sociedades mais justas e mais igualitárias".

(RIBEIRO, 2010, p. 4)

Se o ponto de partida é a universidade - ambiente onde transita a juventude movida por uma consciência dada pela condição de educando - o círculo só se completaria com o envolvimento da sociedade mais ampla, de amplas camadas da população nos debates e nas lutas em uma universidade politizada. Esta é a fala que traduz fortemente o sentimento de que se apossou Darcy Ribeiro na apresentação da edição brasileira, escrito movido pela distância, assinado em Montevidéu, no emblemático Maio de 1968.

A crise das universidades em nossos países latino-americanos foi enfeixada no que Darcy Ribeiro classificou como fruto de um pêndulo que se move entre duas políticas básicas, não apenas distintas, mas opostas, sustentadas com maior ou menor lucidez por todos os universitários: "modernização reflexa e crescimento autônomo". São categorias de análise importantes que de alguma maneira habitaram a reflexão de intelectuais como Guerreiro Ramos em período semelhante. De que maneira países subdesenvolvidos desenhariam políticas de desenvolvimento (e a política universitária é central em um projeto dessa natureza) tendo como quadros de referência os países centrais, portadores de autonomia e capacidade de acumulação econômica e científica que muito os separam dos periféricos? Desconhecer os modelos? Negar-se ao avanço científico? Transportá-los acriticamente como saída ao nosso próprio subdesenvolvimento? Procurar com o modelo universitário desempenhar um papel ativo no esforço de superação do atraso nacional seria a indicação mais recomendada por Darcy, o que não se resolve por decreto, ao contrário, exige esforço intelectual, consciência e vontade política. O modelo tradicional contra o qual o livro pretende arguir resulta da interação "espontânea dos fatores dentro da universidade" que permite perfilar uma política modernizadora que em certos segmentos da vida universitária poderá florescer graças 
à impetuosidade de seus dirigentes. Processo irregular deixaria outros setores da universidade defasados pela razão inversa.

\begin{abstract}
“A política modernizadora aspira apenas a reformar a universidade de modo a torná-la mais eficiente no exercício de funções conservadoras dentro de sociedades dependentes e sujeitas à espoliação neocolonial. A política autonomista aspira a transfigurar a universidade como um passo em direção à transformação da própria sociedade, a fim de lhe permitir, dentro de prazos previsíveis, evoluir da condição de um "proletário externo" destinado a atender as condições de vida e de prosperidade de outras nações, à condição de um povo para si, dono do comando de seu destino e disposto a integrar-se na civilização emergente como uma nação autônoma".

(RIBEIRO, 2010, p. 10)
\end{abstract}

\title{
0 exílio do intelectual crítico
}

Para entender a centralidade da condição - metafórica e biográfica - do exílio -categoria fundamental para a consideração dos impasses e dos dilemas culturais e sociais da América Latina -, na última etapa da trajetória e da produção de Ángel Rama, isto é, entre 1970 e 1983, devemos começar retornando ao contexto histórico imediatamente anterior. Entre 1959, ano da Revolução Cubana, e a década de 1970, período no qual se estabeleceu, consolidou e quebrou uma trama de intensa sociabilidade letrada que definiu uma época na história político-literária do continente, Ángel Rama ocupou um lugar central como núcleo de uma série de espaços de associação, organizador de coleções editoriais, fundador de revistas e participante em colóquios. ${ }^{12}$ Rama foi um dos intelectuais referentes e constitutivos dessa rede, conformada por criadores e críticos culturais da América Latina, seja em seu papel como diretor da seção literária da Revista uruguaia Marcha entre 1959 e 1969, de perfil editorial latino-americanista, ou como parte do

\footnotetext{
${ }^{12}$ Como a crítica argentina Claudia Gilman já estudou em seu livro Entre la pluma y el fusil, Debates y dilemas del escritor revolucionario en América Latina, a comunidade intelectual que se criou nessas décadas atravessou as fronteiras da nacionalidade e encontrou na Revolução Cubana um horizonte de abertura e pertencimento; eles criaram uma agenda intelectual em torno de um ideal que tentou conjugar a eficácia da ação política com a produção e difusão do primeiro cânone de literatura latino-americana de alcance mundial. Ver: GILMAN, Claudia. (2003). Entre la pluma y el fusil. Debates y dilemas del escritor revolucionario en América Latina. Buenos Aires, Siglo XXI.
} 
Comitê de Colaboração da Revista Cubana "Casa de las Américas" (revista central na promoção e difusão da Revolução Cubana) entre 1964 e 1971.13 Na sua extensíssima produção de ensaios, artigos e livros no período, Rama expressou uma aspiração latino-americanista e um ideário internacionalista e cosmopolita, ${ }^{14}$ assim como também sua defesa de uma ideia de intelectual crítico e autônomo perante as demandas de qualquer regime político, inclusive de ordem revolucionária, o que explica seu apoio, mas também sua distância com respeito à Revolução Cubana. ${ }^{15}$

No entanto, já a partir de 1974, momento em que começa a escrever seu diário pessoal, a trajetória e o pensamento do Angel Rama revelam a progressiva dissolução dessa rede de sociabilidade e interlocução latinoamericana, a perda de sua própria capacidade para gerenciá-la, ao mesmo tempo em que tem lugar o abandono da crença na inevitabilidade da revolução pelos intelectuais do período. O que resulta interessante para os objetivos deste trabalho é ver como foi que, nos anos de seu exílio, entre 1977 e 1983, sua concepção do intelectual entra em crise. É tanto o papel do intelectual crítico, ligado à realidade social e suas necessidades, que entra em crise, como a própria ideia de cidadania no contexto do exílio, uma cidadania que se define pelo pertencimento a uma comunidade intelectual não só nacional, mas, sobretudo, latino-americana e, inclusive, cosmopolita. Iremos nos deter em algumas questões relativas à biografia intelectual e também à produção de Ángel Rama, que consideramos importantes para dar conta da crise de sua concepção do intelectual. Enfatizaremos especificamente sua relação com os intelectuais brasileiros, sobretudo com Darcy Ribeiro, o que nos pareceu sintomático de suas concepções e de sua trajetória.

\footnotetext{
${ }^{13}$ Em 1971, Rama se desvinculou da revista devido ao chamado "caso Padilla", escândalo que teve como centro o escritor cubano Heberto Padilla e que provocou a oposição de muitos intelectuais e escritores ao regime. Ver: GILMAN, Claudia. (2012). "Enredos y desenredos de Ángel Rama y Emir Rodríguez Monegal”. Nuevo Texto Crítico. N. 24-25.

${ }^{14}$ Sobre la cuestión del cosmopolitismo en Ángel Rama, ver: JOSIOWICZ, Alejandra. (2008). Redes universales para la crítica latinoamericanista: Rama relee a Martí junto a Rimbaud. Colorado Review of Hispanic Studies, v.6. p.25-38; e (2004). Ángel Rama y el ensayo cosmopolita. Outra Travessia, v.17. p.71-80.

${ }^{15}$ Sobre o tema, ver também: GILMAN, Claudia. (2015). Un llamado de atención sobre ideas recibidas. Cuadernos de Literatura. Vol. XIX. N. 37.
} 
Ángel Rama encontra-se lecionando na Escola de Letras da Universidade Central de Venezuela quando acontece o golpe de Estado militar no Uruguai, em 1973. Antes, em 1970 e até 1972, Rama esteve em Porto Rico, onde lecionou na Universidade de Porto Rico, Campus de Rio Piedras, estabeleceu relações com vários intelectuais da ilha, como Nilita Vientós Gastón, Rosario Ferré e Arcadio Díaz Quiñones, entre outros, colaborou em várias publicações e participou de conferências e bancas. ${ }^{16}$ Rama se tornaria difusor e divulgador da cultura porto-riquenha na América Latina, através da Biblioteca Ayacucho, que incluiu volumes sobre Luis Palés Matos, Eugenio Maria de Hostos e Manuel Zeno Gandía: a partir de sua visão interligada e transnacional da cultura latino-americana.

Já na Venezuela, o governo ditatorial do Uruguai rejeitou sua solicitação de passaporte, razão pela qual foi compelido a adotar a nacionalidade venezuelana. Lá, graças à prosperidade econômica experimentada no país, fruto dos ganhos do petróleo e graças ao apoio do então presidente, Carlos Andrés Pérez, Ángel Rama dirigiu, a partir de 1974, a Biblioteca Ayacucho, na qual canalizou seu projeto de uma cultura latino-americana como superação da "falta de comunicação" entre os países. ${ }^{17}$ Com o pretexto da fundação e da organização do plano da coleção, iniciou um diálogo com uma série de intelectuais latino-americanos. Para nomear só alguns deles, Leopoldo Zea, Roberto Fernádez Retamar, Arturo Roig, Arcádio Díaz Quiñones, Darcy Ribeiro, Berta Ribeiro, Sergio Buarque de Holanda e Antonio Cândido. Ángel Rama já tinha colaborado com Darcy Ribeiro em um projeto editorial no Uruguai. ${ }^{18}$ Após sua chegada ao país como exilado, Ribeiro tinha começado a lecionar como professor na

\footnotetext{
${ }^{16}$ Ver o dossiê da revista Sin nombre (San Juan, Puerto Rico) 1984, sobre Marta Traba e o artigo de Rosario Ferré, "Tres escritores puertorriqueños hablan sobre Ángel Rama" Hispamérica, v. 13, n. 39, 1984. pp. 61-65, que inclui testemunhos de Nilita Vientós Gastón, Enrique Laguerre y Manuel Maldonado Denis. Rama também escreveu um prólogo ao livro de José Luis González, En Nueva York y otras desgracias (1993). Agradecemos a Arcadio Díaz Quiñones pelas referências e pelo relato sobre a passagem de Rama por Puerto Rico e sua influência sobre os intelectuais porto-riquenhos.

${ }^{17}$ RAMA, Ángel. (2001). Diario (1974-1983). Caracas, Ed. Trilce.

${ }^{18}$ Sobre a colaboração de Ángel Rama e Darcy Ribeiro, ver: ROCCA, Pablo. (2015). Ser (ou tornar-se) latino-americano: sobre o diálogo entre Darcy Ribeiro e Ángel Rama (p. 45-50). In: Pablo Rocca; Haydée Ribeiro (Orgs., estudos e notas); Diálogos latino-americanos. Correspondencia entre Ángel Rama, Berta e Darcy Ribeiro. São Paulo, Ed. Global. E também: RIBEIRO, Haydée. (2005). A cultura na perspectiva de Darcy Ribeiro e Ángel Rama. Via atlântica, n. 8.
} 
Faculdade de Humanidades e Ciências de la República em 1964, na cátedra de Antropologia Social e Cultural. Vários de seus cursos eram abertos ao público geral: Rama e outros intelectuais os frequentavam. Foi nesse momento que Rama e Ribeiro criaram e organizaram a Enciclopedia uruguaya. Historia de la civilización uruguaya, coleção de 63 fascículos que saiu entre 1968 e 1969, dedicada à difusão da história, a cultura, a política e as ciências sociais do Uruguai, com a qual colaboraram historiadores, sociólogos, críticos de arte e literatura e economistas. Distribuída a preços accessíveis e destinada a um público amplo, a enciclopédia era vendida em livrarias e bancas de jornal, ao estilo de outras coleções em fascículos do período. ${ }^{19}$ Como o crítico Pablo Rocca já apontou, as contribuições de Ribeiro para a Enciclopédia ajudaram a desviar o projeto do caráter nacionalista e o colocaram frente a frente com questões latino-americanas. Antes, em 1964, o semanário Marcha tinha publicado uma entrevista com Ribeiro feita por Rama com o título "Darcy Ribeiro: una generación brasileña." Nela, Ribeiro é apresentado como intelectual brasileiro exilado, por um lado, mas também como parte da geração de cientistas sociais do país que possibilitaram o amadurecimento das ciências sociais no Brasil e levaram sua visibilidade e relevância ao plano internacional. Ribeiro os caracteriza como uma geração com consciência crítica da realidade brasileira, engajada na luta pela transformação da nação e fortemente determinada pelo espaço da universidade; eles teriam criado uma ciência social própria, como instrumento de ação sobre a realidade social, que integraria a cultura brasileira, abrindo-a aos olhos do mundo. ${ }^{20}$ Ribeiro aparece no artigo como exilado, vozeiro e representante das ciências sociais brasileiras no exterior. ${ }^{21}$

Mas o interesse de Rama pelo diálogo com o Brasil ganhou ainda mais importância no contexto do projeto da Biblioteca Ayacucho. Já para a reunião inicial, convidou Darcy Ribeiro, Caio Prado Júnior, Carlos Drummond de Andrade e Antônio Cândido. Mas, devido ao impedimento imposto

\footnotetext{
${ }^{19}$ ROCCA, Pablo. (2015). Ser (ou tornar-se) latino-americano: sobre o diálogo entre Darcy Ribeiro e Ángel Rama. In: Pablo Rocca; Haydée Ribeiro (Orgs., estudos e notas); Diálogos latinoamericanos. Correspondência entre Ángel Rama, Berta e Darcy Ribeiro. São Paulo, Ed. Global.

${ }^{20}$ RIBEIRO, Darcy: una generación brasileña. Marcha. 29 de maio de 1964. XXV, n. 1207.

${ }^{21}$ Darcy Ribeiro teve impacto importante na Argentina através da edição de As Américas e a Civilização em 1969 pela Centro Editor da América Latina. Ver entrevista a Renzo Pi Hugarte citada em: Ribeiro, Haydée. (2005). A cultura na perspectiva de Darcy Ribeiro e Ángel Rama Via atlântica, n. 8 .
} 
pelo governo militar à saída de Caio Prado, Rama decidiu continuar a colaboração à distância, e solicitou de Darcy Ribeiro e Antônio Cândido a elaboração de uma lista de obras literárias, históricas, sociológicas e antropológicas representativas do Brasil. Como resultado, Rama planejara publicar uns vinte títulos em tradução, incluindo textos de Mário de Andrade, Oswald de Andrade, Graciliano Ramos, Capistrano de Abreu, Sílvio Romero, Joaquim Nabuco, Manuel Antônio de Almeida, Caio Prado Júnior, Lima Barreto, Machado de Assis, Euclides da Cunha, Guimarães Rosa, com prólogos e cronologias de Gilda de Mello e Souza, Antonio Candido, Roberto Schwarz, Walnice Nogueira Galvão, Alfredo Bosi, entre outros. Consciente de seu papel de difusor da cultura brasileira na América hispânica, Rama afirma em carta a Berta Ribeiro: "creio que vou ganhar minha medalha de reconhecimento por parte da cultura brasileira, pelo meu esforço para torná-la conhecida entre os hispano-falantes". ${ }^{22} \mathrm{O}$ diálogo com Darcy e Berta Ribeiro também se tornou importante para o projeto concebido por Rama de relacionar o discurso literário com a antropologia (pioneiro do que seriam, alguns anos mais tarde, os estudos culturais latinoamericanos): cita ambos no seu livro Transculturación narrativa en América Latina, dedicado a Darcy Ribeiro e ao antropólogo John Murra (estudioso do império incaico) como "antropólogos de nossa América". ${ }^{23}$

Para o projeto da Biblioteca Ayacucho, Rama encomenda a Darcy Ribeiro a elaboração do prólogo de Casa Grande e Senzala, no qual devia apresentar o livro para o público hispano-americano, assim como uma cronologia de Gilberto Freyre e uma da história do Brasil. ${ }^{24}$ (Vale a pena ressaltar que cada volume continha uma cronologia em três colunas, dedicadas ao autor e sua obra, à história do país, da América Latina e do mundo.) Ángel Rama corrige e modifica o prólogo e a cronologia elaborados por Ribeiro, dado que os considera "indiscretos", "imprudentes", carentes de algumas informações intelectuais importantes, algo "irreverentes" e pouco objetivos, diminui

\footnotetext{
${ }^{22}$ Carta de 4 de outubro de 1976. In: ROCCA, Pablo; COELHO, Haydée Ribeiro (Org. estudos e notas). Diálogos latino-americanos. Correspondência entre Ángel Rama, Berta e Darcy Ribeiro. São Paulo, Ed. Global. p. 135

${ }^{23}$ RAMA, Ángel. Transculturación narrativa en América Latina. México, Siglo XXI, 1982.

${ }^{24}$ FREYRE, Gilberto. (1977). Casa Grande y Senzala. Caracas: Ed. Ayacucho. Pról. e cronologia de Darcy Ribeiro.
} 
os comentários e modifica algumas informações que julga arbitrárias. ${ }^{25}$ Mesmo com as diferenças metodológicas que ele expressa a respeito de seus trabalhos, chegando a afirmar, ironicamente, "eu sempre disse que os livros de antropologia de Darcy Ribeiro eram romances fascinantes", ${ }^{26}$ Ribeiro não deixa de funcionar para Rama como um modelo de intelectual latino-americano. ${ }^{27}$ Assim, em carta de 1981, solicita-lhe um ensaio para uma antologia do pensamento latino-americano do século XX que estava organizando e afirma: "estou decidido a que você seja a última voz, a do futuro, nesse volume (...). Martí abriu um tempo nosso, profeticamente, e é você quem deve ser a voz profética deste momento revolto, cético, desesperançado, para acender de novo a confiança de todos nós. Não há ninguém que possa fazê-lo senão você. Como dizem os mexicanos, ándele pues." E continua: "Em um artigo para os americanos, sobre exílios, mostro você como o principal exemplo de integração que conheci nessas décadas, com o qual quase justifico indiretamente os ditadores" ${ }^{28}$ Como se vê, Ribeiro é, para Rama, exemplo de uma voz "profética", a voz "do futuro", da retomada da "confiança" no latino-americano, em um momento de ditadura e derrota intelectual. É precisamente na sua condição de exilado, unida à sua concepção da integração da cultura latino-americana, ao mesmo tempo utópica e "ardentemente polémica", que Ribeiro se torna um intelectual paradigmático para Rama.

O artigo sobre exílio que Rama menciona na sua carta já tinha sido publicado anteriormente, em 1974, em um número da Revista venezuelana Nueva Sociedad dedicado às produções culturais e intelectuais dos latinoamericanos no exílio, que incluía artigos do uruguaio Eduardo Galeano, do argentino Noé Jitrik, do chileno Ariel Dorfman e do paraguaio Augusto Roa

\footnotetext{
${ }^{25}$ Rama observa, sobre seu trabalho de correição do prólogo de Ribeiro: "por alguns momentos pensei que tinha ocupado o lugar de Berta e que apenas me restava, como a ela, a tarefa de escrever diretamente para você os livros". ROCCA, Pablo; RIBEIRO, Haydée (Orgs., estudos e notas). Diálogos latino-americanos. Correspondência entre Ángel Rama, Berta e Darcy Ribeiro. São Paulo, Ed. Global. p. 81.

${ }^{26}$ ROCCA, Pablo; RIBEIRO, Haydée (Org., estudos e notas). Diálogos latino-americanos. Correspondência entre Ángel Rama, Berta e Darcy Ribeiro. São Paulo, Ed. Global. p. 115.

${ }^{27}$ No plano da coleção da Biblioteca, também se encontrava a publicação do livro de Darcy: As Américas e a Civilização, que viria a ser publicado só após a morte de Rama, em 1992.

${ }^{28}$ Carta de 15 de abril de 1981. ROCCA, Pablo; RIBEIRO, Haydée (Orgs., estudos e notas). Diálogos latino-americanos. Correspondência entre Ángel Rama, Berta e Darcy Ribeiro. São Paulo, Ed. Global. p. 99.
} 
Bastos, além de autores do Peru e da Nicarágua. ${ }^{29}$ No ano de 1981, Rama republicou o texto para um novo dossiê sobre exílio que organizou para a revista norte-americana Review: Literature and Arts of the Americas - a qual veiculava traduções de textos literários e artigos de diferentes países da América Latina. O dossiê sobre o exílio na América Latina também incluiu um texto de Julio Cortázar: "The Fellowship of Exile", um de Augusto Roa Bastos, "The Exiles of the Paraguayan Writer" e outro de Fernando Alegría sobre o mesmo tema. ${ }^{30}$

De fato, em numerosos artigos desses anos, assim como em seu diário pessoal e suas cartas, Rama reflete sobre o exílio intelectual latino-americano, tema que o preocupava em um sentido tanto teórico quanto pessoal. Examinaremos inicialmente a questão no seu diário, para depois passar aos artigos. Rama escreveu o diário entre 1974 e 1983, período que abarca sua estada na Venezuela, nos Estados Unidos, e brevemente na França, até sua morte. Nesses cadernos, ele escreve muito intensamente sobre a condição do exílio: expressa a experiência de instabilidade, insegurança e deslocamento decorrente das múltiplas mudanças pessoais e profissionais, da carência de passaporte, de residência e, sobretudo, de pertencimento a uma comunidade nacional e cívica. Mas o exílio vai além de uma experiência profissional ou pessoal: também define seu posicionamento intelectual no contexto da Guerra Fria. Assim, opõe-se aos intelectuais que reproduziam de modo acrítico o discurso da Revolução Cubana: é crítico da atuação de Roberto Fernández Retamar e de Julio Cortázar, enfatizando a necessidade de independência e autonomia do intelectual diante do poder político. Mas também desconfia da vida acadêmica universitária dos Estados Unidos, receoso de viver "com os poderes gringos invisíveis sobre uno" ${ }^{\prime 1}$, e preocupado com o que percebe como um afastamento do mundo, uma "especialização da ação intelectual", uma falta de compromisso com a sociedade que "queda fora, mais além dos limites do campus". ${ }^{32}$ Esse complicado posicionamento resulta em uma espécie de entre-lugar, que Rama cria para si mesmo: entre ideologias, tradições de pensamento,

\footnotetext{
${ }^{29}$ O dossiê levou o título América Latina: ¿una literatura exiliada?. Nueva sociedad N. 35. Março-Abril 1978.

${ }^{30}$ Review: Literature and Arts of the Americas. n. 30. Sept.-Dec.1981.

${ }^{31}$ Diario (1974-1983). Caracas, Ed. Trilce, 2001. p. 77.

32 Diario (1974-1983). Caracas, Ed. Trilce, 2001. p. 70.
} 
posições éticas e modos diferentes e até opostos de pensar a atividade intelectual.

Tudo isso o coloca em um espaço restrito, paranoico e claustrofóbico. Em Caracas, sente-se rejeitado pelo meio intelectual venezuelano, que julga xenófobo, corrupto e provinciano, e escreve: "Vivo con la sensación del acosado (...) Y me temo que si eso cambiara sentiría que ya es tarde y que no me podrán consolar de lo que me han hecho padecer. Bien caro me han cobrado el pan del exilio." ${ }^{\prime 33}$ Em vários momentos do diário, Rama denuncia a posição defensiva ligada ao culto do passado tradicional e folclórico e a um provincianismo falso e populista, e afirma a necessidade de novos equilíbrios culturais que relacionem as identidades nacionais com as tendências culturais modernas e cosmopolitas. ${ }^{34}$ Esse tipo de considerações também determina seu posicionamento como intelectual. Assim, Rama sente-se representante de uma comunidade intelectual latinoamericana que, em lugar da defesa de uma autenticidade idiossincrática, propõe o diálogo entre o local e a modernidade cosmopolita. Identifica-se com o venezuelano, tutor e mentor de Bolívar, e também exilado Simón Rodriguez, sobre o qual afirma:

"Duele su triste vida y acompaña. Esos decenios por escuálidas
ciudades americanas, sin recuerdos, atendiendo pobres negocios,
viviendo de la caridad; esa muerte en un caserío ecuatoriano,
río arriba, con los dos baúles llenos de papeles y nada más; esa
continua frustración de pensar mejor que nadie y no ser oído,
ni atendido ni respetado; esa inteligencia, condenada por tal, en
medio del caos, los apetitos desatados, la garrulería, la confusión.
Todo define al intelectual en una América cruda, mal amasada" ${ }^{35}$

A passagem define a condição do exílio como determinante do intelectual latino-americano: aquele que não tem inserção fixa nas instituições nem espaço social, pobre, desprovido de reconhecimento, cuja

\footnotetext{
${ }^{33}$ Diario (1974-1983). Caracas, Ed. Trilce, 2001. p. 78.

${ }^{34}$ Afirma: "Sólo un desarrollo armonioso y valiente de ambas coordenadas, con lo que ello implica de tenaz esfuerzo para dominar la cultura del mundo presente, permitirá integrar la nacionalidad, desprenderla del provincianismo, sin por eso perder la identidad fundamental. Y de paso disolver la resistencia al elemento extranjero, reconociendo su calidad de heraldos de ese mundo presente y dotándolos de una fuerte y sabrosa impregnación local." Diario (1974-1983). Caracas, Ed. Trilce, 2001. p.83.
}

${ }^{35}$ Diario (1974-1983). Caracas, Ed. Trilce, 2001. p. 112. 
única possessão é a própria perspectiva crítica, alheio aos desejos e ânsias dos outros cidadãos. O caráter imaturo do meio latino-americano, "cru", "mal amassado", pareceria determinar essa condição do intelectual como exilado. No entanto, os anos que passou nos Estados Unidos, logo após sua renúncia à Escola de Letras da Universidade Central de Venezuela em 1978, no Middlebury College, nas Universidades de Maryland e Princeton, não lhe trazem reconhecimento nem inserção institucional. Pelo contrário, queixa-se da "mesquinhez" do ambiente intelectual, que julga pobre e reducionista, e dos professores: “ipor qué se dedican a la literatura y al arte, si nada tienen que ver, orgánicamente, con ellos?" (RAMA, 2001, p. 127), e os chama "jibarizadores de lo bello, de lo fuerte, de lo verdadero." (RAMA, 2001, p. 128). Contrasta aquele ambiente com o modelo de intelectual-professor que observou na Universidade de Campinas, durante uma viagem de dez dias que fez para um colóquio organizado por Antônio Cândido, do qual se sente imediatamente partícipe: "ponen pasión y juegan su vida en lo que dicen (...). Están vivos en el curso arrollador del arte y el conocimiento: eso es central para ellos, es el sentido de la vida. $Y$ las cosas no están separadas, el arte, el deseo, la política, el júbilo y el miedo, son todas cosas que van juntas, con el agregado de que exigen como pago la gracia." (Idem, p.128). Essa concepção apaixonada, vital, da tarefa intelectual como inseparável da política, da cultura e da própria experiência subjetiva está no centro de seu modelo de intelectual crítico, cuja produção resulta politizada e até estetizada. Essa concepção contrasta com as observações de Rama nos Estados Unidos. Lá vê os professores "recluídos", "perdidos do mundo em um ghetto intelectual" (p. 135). Escreve:

"Como si estuvieran fuera de la corriente principal de la cultura
del país, contemplándola y examinándola a veces, ignorándola
frecuentemente, ligados entre sí con otros ghettos similares en
diversos puntos del mundo. Es, en el fondo, la diferencia con los
intelectuales latinoamericanos que no han alcanzado ese grado
de especialización quizás, y que en definitiva son profesores
porque son escritores y a veces por añadidura políticos y cumplen
simultáneamente todas las funciones en el centro de la vida social,
estatuyendo el principio de reverencia al intelectual como guía,
maestro, estudioso, profeta, y, en ocasiones, hombre de acción”.
(RAMA, 2001, p. 136).

Rama analisa o fenômeno não como decorrente de níveis ou graus de especialização ou desenvolvimento dos países, mas de modelos culturais 
distintos: o anglo-saxão, especializado, afastado da sociedade e conectado a outras comunidades autônomas e equivalentes, e o latino, herdeiro do modelo francês, no qual o intelectual é tanto homem de saber quanto homem de ação, professor, escritor, político, nunca desligado de seu entorno social. Ao mesmo tempo em que é crítico dos intelectuais politizados que encarnam qualquer sentido profético e paternalista, Rama sente-se um "outsider" na academia norte-americana, com seus critérios de profissionalização e competição. Quando assiste a uma palestra de Júlio Cortázar em Paris, confessa-se "abominado dos escritores metidos a políticos: acabam fazendo mal as duas coisas". Acusa-o de dizer obviedades sobre os regimes militares, sobre o socialismo como simples panaceia, sobre os escritores engajados e sobre as bondades políticas do regime cubano. E afirma:

“a mi me volvió a plantear esta espina sobre los prejuicios que
estos intelectuales ignorantes de la realidad social, económica y
política de nuestros pueblos provocan en las jóvenes generaciones
que creen en ellos (porque son buenos escritores no porque sean
políticos buenos) y están dispuestos a aceptar sus juicios. La
extrapolación es evidente: aprovechando la autoridad ganada
en el campo de la "literatura pura" se la usa para impartir
una doctrina sobre asuntos que le son enteramente ajenos y
donde no ha habido prueba de ningún tipo de competencia o
conocimiento serio. Desgraciado equívoco. He conocido sus
desgraciadas consecuencias en el pasado y nada parece que ellas
hayan contribuido a hacer más serias y responsables las palabras
políticas que hoy siguen pronunciando los intelectuales". ${ }^{36}$

O problema que percebe no discurso de Cortázar não tem a ver simplesmente com sua falta de informação a respeito da situação política, econômica e social, mas, sobretudo, com o alargamento da legitimidade que o escritor conseguiu no terreno literário, instrumentado na esfera política. Trata-se do dilema intelectual que nasce com o célebre "J'accuse!", de Émile Zola. Não é das mediações simbólicas e das suas competências específicas que o intelectual precisa partir para viabilizar seu discurso?, pergunta-se Rama. Caso contrário, arrisca-se a uma posição paternalista e arbitrária, como aquela de Cortázar. Mas se o problema, no caso latino-americano,

${ }^{36}$ RAMA, Ángel. (2001). Diario (1974-1983). Caracas: Ed. Trilce. p. 154. 
é a extrapolação política da autoridade intelectual, na academia norteamericana seria o esvaziamento dos debates, a extrema profissionalização e a especialização do conhecimento:

\begin{abstract}
lo normal es que los profesores no intercambien nada, a pesar de la complicadísima estructura de seminarios, coloquios y diálogos (...) Cada uno está en lo suyo y a veces pienso que tienen miedo, que eso es lo dominante, porque preservan lo que hacen de todo debate que pueda ponerlo en peligro. O quizás de ilegítimas apropiaciones: el propio Claudio [Velis] me repetía hoy "eso de la ciudad letrada publícalo ya en algún artículo" para registrar el copyright. ${ }^{37}$
\end{abstract}

Ángel Rama percebe a internalização pelos intelectuais da noção das ideias como mercadorias, com foco nos benefícios materiais e simbólicos derivados da propriedade intelectual, mais do que nos processos de seu debate e produção. Nesse caso, trata-se de uma atividade intelectual sem eficácia social e sem significação política, marcada pela atitude competitiva e individualista. É claro que parte das reflexões de Rama estão ligadas ao sentimento de culpa, vivido por muitos intelectuais do período, e da necessidade de vigilância diante do suposto perigo de ser cooptado pelos Estados Unidos. Seu posicionamento perante modelos opostos do intelectual o coloca em um espaço duplamente exiliado.

Se no Diário Rama deixa transparecer um posicionamento duplamente reticente, nos artigos publicados nesses anos leva ainda mais além sua elaboração da condição do intelectual no exílio. Assim, no ensaio "La riesgosa navegación del escritor exiliado", publicado pela primeira vez em espanhol, em 1978, e, mais tarde, em inglês em 1981, com o título "Founding the Latin American Literary Community", estabelece um paralelo entre os escritores exilados por causas políticas, devido aos regimes ditatoriais, e as populações migrantes por causas econômicas. Equipara ambas migrações - a dos profissionais e professores e a dos operários e camponeses - como diásporas latino-americanas, movimentações entre países latino-americanos e fora da América Latina que estariam ligadas a uma equivalente conjuntura econômica, social e política. Através dessa relação entre intelectuais exilados e trabalhadores migrantes, considera

${ }^{37}$ RAMA, Ángel. (2001). Diario (1974-1983). Caracas: Ed. Trilce. p. 140. 
o exílio como processo social abrangente, do qual participariam tanto trabalhadores, operários e camponeses, quanto profissionais, professores e técnicos especializados. Desse modo, a condição do exílio determinaria um novo modo transnacional de pensar a cidadania e os cidadãos, que começariam a circular por comunidades espalhadas em nível planetário.

Seria só a partir do exílio e da emigração, causada pelos regimes ditatoriais, que grupos inteiros de intelectuais latino-americanos teriam descoberto a "América indígena", a "América negra", e que se teria acelerado o intercâmbio entre os intelectuais de diferentes países, criandose uma visão integrada do continente. $\mathrm{O}$ exemplo paradigmático seria o caso dos intelectuais brasileiros exilados, que haveriam estabelecido comunicações culturais inéditas com a América Hispânica:

Pienso que un libro imaginativo y talentoso como Las Américas y la Civilización, de Darcy Ribeiro, hubiera sido imposible sin estos largos años de exilio que le permitieron recorrer y vivir por años en diversos países y zonas del continente. Del mismo modo la experiencia en las artes plásticas de Pedroza, en la poesía de Ferreira Gullar, en las ciencias políticas de Julião. ${ }^{38}$

Darcy Ribeiro funciona, mais uma vez, como modelo do intelectual latinoamericano exilado, "vivendo em países e diversas áreas do continente", "descobrindo" ou redescobrindo a América Hispânica e estabelecendo laços culturais entre esses países e o Brasil. Se anteriormente toda visão integradora da América Latina teria provindo da Europa ou dos Estados Unidos, graças ao exílio seria possível criar novas percepções do conjunto, enfatizando circunstâncias econômicas, sociais e culturais comuns.

O tipo de produção decorrente do exílio, segundo Rama, estaria ligada com a derrota, "literatura" de derrotados, ainda mais profícua que a militante anterior. Nesse sentido, o exilado se contrapõe à figura sacralizada, heroica e politizada do intelectual que se pretende elevado por sobre a sociedade, "vão" e "exibicionista". Esses escritores-políticos, segundo Rama, acabam sendo "maus escritores e maus políticos". Em lugar de guia indiferenciado ou porta-voz de um partido, o intelectual deveria contribuir partindo de suas circunstâncias - as do exílio - e sem abandonar seu "campo específico"

${ }^{38}$ RAMA, Ángel. Nueva sociedad, n. 35. Março-abril 1978. p. 99-100. 
e as necessidades da sua comunidade - exilada e migrante. De fato, ele assinala três públicos para os quais escreveria o escritor-intelectual no exílio: o do país receptor, o de seu país de origem e o da diáspora, sendo o último o mais relevante. A aliança estratégica traçada por Rama entre o intelectual exiliado e as populações migrantes responde justamente à intenção de conjugar produção cultural e responsabilidade social, retomando a eficácia social da tarefa intelectual, e evitando a sacralização ou a visão paternalista e partidária do intelectual. O exílio seria, para ele, a circunstância que permitiria ao intelectual crítico cumprir seu papel junto à comunidade.

Rama desenvolveu mais, em outros ensaios, suas reflexões sobre a produção de uma literatura derrotada no exílio, assim como dos distintos públicos aos que podia estar destinada. ${ }^{39}$ Nesses anos, também escreveu uma série de artigos de intervenção sobre os "dissidentes" e a "dissidência" dos intelectuais exilados do regime comunista soviético, críticos de suas diretivas ideológicas. Esse tipo de "dissidência", que supera as barreiras nacionais e abre-se ao âmbito intelectual transnacional, parecia-lhe fundamental para repensar o papel das esquerdas na América Latina.$^{40} \mathrm{De}$ fato, a condição do exilado tornou-se ainda mais intensa nos dois últimos anos de sua vida, devido à polêmica aberta pela rejeição de seu visto nos Estados Unidos.

Mas o que interessa particularmente para nossos propósitos é a ambivalência que aparece no seu modelo de intelectual exilado: ao mesmo tempo em que é capaz de perspectiva crítica e potencial transformador, partindo dos recursos intelectuais próprios de seu campo disciplinar e de sua coerência interna, o intelectual está ativamente inserido na vida prática, é militante e prometeico, ligado de modo mais ou menos orgânico com as circunstâncias nas quais vivem os trabalhadores migrantes. É essa ambivalência a que explica sua admiração pelo modelo da Universidade de Campinas e pela figura de Antonio Candido, que operou como o outro grande mediador de sua visão do Brasil, ao mesmo tempo em que torna inteligível a centralidade da figura de Darcy Ribeiro (que também lhe gerava irritação acadêmica e disciplinar) como modelo de intelectual exilado, cujo caráter prometeico o tornaria uma figura fundamental para

39 RAMA, Ángel (1993). Las últimas novelas de Donoso. La metamorfosis del exilio latinoamericano. In: La riesgosa navegación del escritor exiliado. Montevideo, Arca.

${ }^{40}$ Trata-se de um conjunto de artigos publicados no jornal venezuelano "El Universal" com o título de "Los dissidentes". 
uma futura (e utópica) integração latino-americana. Inclusive quando partem de pertencimentos disciplinares diferentes - a crítica literária e a antropologia - Ángel Rama e Darcy Ribeiro aparecem como unidos pela experiência do exílio dentro e fora da América Latina, e pela reflexão sobre o modelo de intelectual e seu papel dentro e fora da universidade.

\section{Exílio, exílios}

O percurso feito pelas trajetórias desses dois intelectuais nos permitiu um contato com questões variadas e, em algum sentido, profundamente ligadas ao tempo presente. No caso de Darcy Ribeiro, já há registro dos embates que provocou e que enfrentou com relação ao processo de institucionalização das Ciências Sociais no Brasil contra o que a virulência de nosso intelectual não fez qualquer cerimônia. ${ }^{41}$ Sua volta ao Brasil em meados dos anos 70 encontrou parcela significativa dos intelectuais brasileiros mobilizados em torno de instituições e programas de Pós-Graduação montados em moldes que mais se assemelhavam ao que ele próprio criticara em seu antinorteamericanismo. Não se tratava mais de apenas um choque de gerações - já que os mais novos não o reconheceram como alguém que ocupasse liderança intelectual em seu campo de atuação. A resistência ultrapassava o limite geracional. Dizia respeito a uma discrepância entre o modelo de profissionalização das Ciências Sociais e a concepção que cultivara em seu distanciamento quando no exílio.

No caso do Rama, a centralidade da categoria do exílio para entender as ambivalências de sua concepção do intelectual, entre a crítica e a militância, revela-se tanto na sua produção ensaística menos frequentada pela crítica quanto em seus escritos pessoais, diário e cartas. O legado dos problemas postos por eles, isto é, a relação entre saber universitário e política, dilemas da profissionalização e da especialização do intelectual e a dívida da própria instituição universitária perante a sociedade ainda são da mais sensível atualidade. A experiência do exílio fortaleceu esse tipo de percepção do lugar desses intelectuais na vida cultural de seus países, e a volta do exílio criou, em alguma dimensão, um exílio da própria condição de intelectual na comunidade acadêmica. Este foi, indiscutivelmente, o caso de Darcy

${ }^{41}$ BOMENY, Helena (2001). Darcy Ribeiro. Sociologia de um indisciplinado. Belo Horizonte, Editora UFMG. 
Ribeiro no Brasil. Ángel Rama, precursor involuntário das possibilidades e dos problemas dos estudos culturais nos Estados Unidos, é, ainda hoje, objeto tanto de modismos quanto de argutas críticas que apontam para os dilemas teórico-metodológicos de sua obra. ${ }^{42}$

Uma última nota, à guisa de conclusão, foi inevitável depois desse percurso. Encontrar outros personagens que, de espaço distinto, encontraram também entre latino-americanos uma espécie de pátria intelectual. A interlocução de Richard Morse, o historiador norte-americano exilado em própria terra, com esses intelectuais latino-americanos, brasileiros em particular, amplia o sentido de exílio que nos motivou a escrita deste texto. Se os sentimentos são semelhantes - isolamento, deslocamento, privação, desterro, sofrimento, incomunicação - o espaço geográfico onde afloram pode ser externo ou interno, o que nos deixa com a convicção de que são múltiplos e nem sempre controláveis os efeitos da interação humana ou da falta dela, e, em nosso caso, da interlocução intelectual ou seu impedimento.

\section{Referências}

AVELAR, Idelber.

(1999). The Untimely Present: Post-dictatorial Latin American Fiction and The Task of Mourning. Durham, Duke Univ. Press.

BOMENY, Helena.

(2001). Darcy Ribeiro. Sociologia de um indisciplinado. Belo Horizonte, Editora UFMG.

BURKE, Peter

(2017). Exiles and Expatriates in the History of Knowledge, 1500-2000. Waltham, Brandeis Univ. Press.

DOSSE, François.

(2009). 0 desafio biográfico. Escrever uma vida. São Paulo, Edusp.

FERRÉ, Rosario.

(1984). Tres escritores puertorriqueños hablan sobre Ángel Rama. Hispamérica, v. 13, n. 39, pp. 61-65.
FREYRE, Gilberto.

(1977). Casa Grande y Senzala. Pról. Y cronologia de Darcy Ribeiro. Caracas, Ed. Ayacucho.

GARRAMUÑo, Florencia.

(2006). El árbol y el bosque: La ciudad letrada y su concepto de poder. Prismas, n.10, pp. 195197.

GILMAN, Claudia

(2012). Enredos y desenredos de Ángel Rama y Emir Rodríguez Monegal. Nuevo Texto Crítico. N. 24-25.

GILMAN, Claudia.

(2003). Entre la pluma y el fusil. Debates y dilemas del escritor revolucionario en América Latina. Buenos Aires, Siglo XXI.

GILMAN, Claudia.

(2015). Un llamado de atención sobre ideas recibidas. Cuadernos de Literatura. Vol. XIX. n. 37.

\footnotetext{
${ }^{42}$ Ver: Dossiê La ciudad letrada hacia una historia de las elites intelectuales en América Latina. Prismas. n. 10, 2006.
} 
GRAMSCI, Antonio.

(2001). Cadernos do cárcere. vol. 2. Os intelectuais. 0 princípio educativo. Jornalismo. Rio de Janeiro, Civilização Brasileira.

JOSIOWICZ, Alejandra.

(2014). Ángel Rama y el ensayo cosmopolita. Outra Travessia, v.17, p.71-80.

JOSIOWICZ, Alejandra.

(2008). Redes universales para la crítica latinoamericanista: Rama relee a Martí junto a Rimbaud. Colorado Review of Hispanic Studies, v.6, p.25 38 .

RAMA, Ángel. (2001). Diario (1974-1983). Caracas, Ed. Trilce.

RAMA, Angel.

(1993). “La riesgosa navegación del escritor exiliado". Nueva Sociedad. Nro. 35. Marçoabril 1978, p. 95-105..

RAMA, Ángel.

(1982). Transculturación narrativa en América Latina. México, Siglo XXI.

RAMA, Ángel e CANDID0, Antonio. Un proyecto latino-americano. Antonio Candido \& Angel Rama. Correspondencia. Ed. Pról.; e notas de Pablo Rocca. Montevideo, Ed. Estuario, 2016

RIBEIR0, Darcy.

(2010). Darcy no bolso. Brasília, Editora UnB.
RIBEIR0, Darcy

(1964). Una generación brasileña. Marcha. 29 de maio de 1964. XXV, n. 1207.

RIBEIR0, Haydée.

(2005). A cultura na perspectiva de Darcy Ribeiro e Ángel Rama. Via atlântica, n. 8.

ROCCA, Pablo.

(2006). Ángel Rama, Emir Rodríguez Monegal y el Brasil: Dos caras de un proyecto latinoamericano. Montevideo, Banda Oriental.

ROCCA, Pablo; RIBEIRO, Haydée Coelho (org.). (2015). Diálogos latino-americanos. Correspondencia entre Ángel Rama, Berta e Darcy Ribeiro. São Paulo, Ed. Global.

RUFINELLI, Jorge.

(1993). Angel Rama, Marcha y la crítica literária latino-americana en los 60s. Casa de las Américas, vol. 34, n.192.

SAID, Edward.

(1994). Representations of the Intellectual. New York, Vintage Books.

\section{Recebido em}

fevereiro de 2017

\section{Aprovado em}

março de 2017 